\title{
Alguns aspectos da privatizaçã̃o educativa na América Latina
}

\section{JUAN CARLOS TEDESCO}

análise e os debates sobre a privatização do ensino despertam,
atualmente, cada vez maior interesse por parte dos especia-
listas e responsáveis da educação. As razóes que justificam a reatualizaçáo deste antigo debate educativo estáo estritamente associadas aos processos de reforma do Estado que têm lugar tanto nos países desenvolvidos como nos países em desenvolvimento.

Neste contexto, é possível observar modificação significativa nos termos tradicionais com os quais se analisou o tema do ensino privado. Como se sabe, o debate tradicional em torno do ensino público e privado girou fundamentalmente sobre um eixo ideológico: tratava-se, em definitivo, de uma luta pelo controle das instituiçóes responsáveis pelo processo de socialização das pessoas. O caráter ideológico da discussão baseava-se em que o conteúdo do processo socializador oferecido por essas instituiçóes era substancialmente diferente. $O$ Estado, com uma proposta secularizadora, competia com outras agências tradicionais, especialmente a Igreja, pelo controle da socialização de certos setores da populaçáo, embora, em outros, deu-se em torno da formação das elites.

Atualmente, por outro lado, esta discussão inclui um número mais amplo de eixos, de atores e de variáveis. Do ponto de vista dos atores, o setor não-governamental comprometido com açóes educativas (denominação com a qual hoje se designa o setor privado) inclui uma diversidade muito ampla de instituiçóes com diferente poder socializador. Em relação às variáveis, também se observam mudanças significativas. Ao eixo ideológico, que hoje se define muito mais em termos culturais (reivindicaçóes lingüísticas, autonomias locais, etc.) se agregam os aspectos financeiros e de gestáo, que ocupam um lugar tanto ou mais destacado que os aspectos ideológicos.

A ampliação do debate está, ademais, associada a uma forte revalorização da privatização como estratégia mais apropriada para resolver os problemas de eficiência e qualidade nos serviços públicos. Neste sentido, os principais argumentos que se mencionam para justificar a 
necessidade de expandir o ensino privado são, ao menos, os seguintes:

1. A pressáo de determinados grupos para manter seus padrōes culturais. Neste caso, a religiáo é um fator muito importante. A Igreja Católica, o Islá, etc. desenvolveram sistemas paralelos de educação, onde os padrōes culturais ocupam um importante lugar no desenho curricular. Em muitos desses casos, os grupos religiosos demandam subsídios financeiros públicos para sustentar as atividades das escolas.

2. O desafio de melhorar a qualidade da educação em contextos de restrição orçamentária. De acordo com esta assertiva, o ensino privado compensaria as dificuldades do setor público para absorver a demanda educativa, particularmente nos níveis superiores do sistema.

3. A necessidade de dinamizar o funcionamento das instituiçóes educativas. Na última década expandiu-se a convicção segundo a qual o ensino privado permite aos pais exercer o direito de escolher a educação de seus filhos e que aquele (ou um sistema misto, público e privado) estimula a eficiência e o dinamismo das instituiçóes (1).

4. O maior interesse privado pela educação, em virtude da revalorizaçáo do conhecimento como fator de produção. Neste sentido, a necessidade de aumentar a competitividade econômica está produzindo uma mudança de enfoque muito significativa, referente à capacitaçáo dos recursos humanos e à produção de conhecimentos, que colocam novamente a educaçáo na agenda de prioridades das inversóes privadas.

Algumas instituiçóes de cooperaçáo internacional apóiam explicitamente esta opçáo de política educativa. O Banco Mundial, por exemplo, tem sustentado uma política favorável à privatização da educação. Segundo seus estudos, a privatização oferece aos pais e à comunidade a possibilidade de um controle mais direto sobre o pessoal e a direçáo das escolas, permite aos pais estabelecer padróes de qualidade para a educação de seus filhos, incrementa a habilidade dos professores, administradores e pais para adaptar os programas às necessidades e condiçōes da comunidade, estimula a possibilidade de obter financiamento da comunidade para as atividades da escola e melhora a eficiência para estimular a competência entre os estabelecimentos (2).

No entanto, as evidências empíricas disponíveis e as análises teóricas em favor ou contra esses argumentos não são conclusivas. $O$ propósito deste artigo consiste, por isso, em apresentar os dados sobre a evoluçáo da cobertura do ensino privado nos últimos anos e discutir as possibilidades de que ela cumpra com os prognósticos anunciados por seus defensores, no contexto dos países em desenvolvimento particular- 
mente afetados por situações de crise econômica.

Esta análise parte de uma constatação importante: a atual situaçáo social e econômica mundial mostra o fracasso ou o menor êxito relativo tanto às experiências de monopólio estatal da atividade econômica e dos serviços sociais como às políticas ultraliberais de desregulamentaçáo. Ao contrário, o maior grau de êxito tem sido obtido pelas experiências de capitalismo organizado, como Japáo e Alemanha, ou de capitalismo com forte regulamentação e presença do Estado no sistema bancário, como França, Itália e Coréia (3). Deste ponto de vista, parece necessário introduzir uma certa dose de ceticismo acerca das posiçóes que aconselham universalizar um determinado estilo de estratégia política, à margem dos contextos sociais, econômicos e culturais e à margem, também, das experiências históricas concretas dos países considerados.

Produz-se, atualmente, uma efetiva privatizaçáo da educação?

Em diversos estudos recentes, baseados no clima intelectual e político resenhado no ponto anterior, afirma-se que nas últimas décadas produziu-se uma expansão importante do ensino privado em todos os níveis e que esta tendência será mantida ou intensificada.

A dificuldade mais séria para avançar na comprovação destas hipóteses reside na carência de informação confiável e exaustiva. No entanto, as evidências disponíveis não permitem sustentar as hipóteses de forma categórica.

Em relação ao ensino primário, o Quadro 1 mostra que na última década não se produziram modificaçóes significativas na distribuiçáo da matrícula nem nos países desenvolvidos nem nos países em desenvolvimento. O setor privado absorve entre 10 e $15 \%$ da matrícula, salvo no caso da Oceania, onde alcança quase $25 \%$.

No caso do ensino secundário (Quadro 2), por outro lado, observam-se dois fenômenos importantes. Em primeiro lugar, uma diferença significativa no papel que joga o setor privado nos países desenvolvidos e nos países em desenvolvimento. Enquanto, nos primeiros, o setor privado atende uma porcentagem de cerca de $15 \%$ da matrícula (semelhante ao registrado no ensino primário), a porcentagem de matrícula privada nos países em desenvolvimento alcança quase $30 \%$.

Em segundo lugar, os dados indicam que, nos últimos anos, enquanto nos países desenvolvidos a situação manteve-se estável, com leve tendência ao aumento do setor privado, nos países em desenvolvimento produziu-se um notório descenso. 


\section{Quadro 1}

Matrícula no ensino primário privado (\%) 1975-1985

\begin{tabular}{l|r|r|r}
\hline & 1975 & 1980 & 1985 \\
\hline África & 15.5 & 11.6 & 12.8 \\
América do Norte & 10.9 & 9.6 & 10.2 \\
América do Sul & 14.0 & 13.9 & 14.1 \\
Ásia & 10.0 & 10.2 & 9.1 \\
Europa & 15.5 & 16.4 & 17.6 \\
Oceania & 21.9 & 21.6 & 24.1 \\
\hline Países desenvolvidos & 12.0 & 13.3 & 11.8 \\
Países em desenvolvimento & 12.6 & 11.9 & 11.7 \\
\hline Total & 12.4 & 11.7 & 11.7 \\
\hline
\end{tabular}

FONTE: Unesco - Development of Private Enrolment First and Second Level Education - 1975-1985. Paris, maio de 1989.

\section{Quadro 2}

Matrícula no ensino secundário geral privado

$$
\text { (\%) - 1975-1985 }
$$

\begin{tabular}{l|c|c|c}
\hline & 1975 & 1980 & 1985 \\
\hline África & 19.5 & 14.5 & 15.9 \\
América do Norte & 10.0 & 10.8 & 10.7 \\
América do Sul & 31.6 & 28.1 & 27.1 \\
Ásia & 33.0 & 30.0 & 29.3 \\
Europa & 16.9 & 16.3 & 17.5 \\
Oceania & 23.5 & 25.9 & 25.8 \\
\hline Países desenvolvidos & 13.2 & 13.2 & 14.0 \\
Países em desenvolvimento & 34.9 & 29.7 & 28.0 \\
\hline Total & 20.6 & 20.0 & 20.9 \\
\hline
\end{tabular}

FONTE: idem Quadro 1 
Em relação ao ensino pré-primário, nível onde tradicionalmente o papel do setor privado tem sido mais significativo, a informaçáo disponível é menos exaustiva e confiável. $O$ Quadro 3 indica a evoluçáo da matrícula de ensino pré-escola privado em algumas regióes. Ali se observa que - salvo nos países do Sudeste asiático, onde a cobertura privada é significativamente baixa - no resto das regiōes as porcentagens são próximas ou superiores a 50\%. Mas o mais importante é observar que, também neste nível, produziu-se uma diminuição relativa da matrícula do setor privado, particularmente significativa no caso da América Latina.

\section{Quadro 3}

Alunos inscritos em estabelecimentos privados

(\%) - Educaçáo pré-escolar, países em desenvolvimento, 1975-1987.

\begin{tabular}{l|c|c}
\hline & 1975 & 1987 \\
\hline África subsahariana & 57 & 54 \\
Estados árabes & 83 & 81 \\
América Latina e Caribe & 44 & 26 \\
Ásia do Leste & 12 & 11 \\
Oceania & 44 & 46 \\
\hline
\end{tabular}

FONTE: Unesco, Oficina de Estatísticas, 1990 (Education de base et Alphabetisation. Indicateurs statistiques dans le monde. ST-90/WS-1).

O aumento da matrícula pública no nível pré-escolar está associado ao significativo crescimento da dita matrícula nas últimas décadas. Neste sentido, pode-se sustentar que, na média, o ciclo pré-escolar incorpora setores tradicionalmente excluídos (filhos de famílias de setores de baixos recursos), aumentando a responsabilidade do setor público. Dito de outra maneira, o Estado parece ser o setor mais dinâmico para satisfazer a demanda educativa da populaçáo que vive em condiçóes de pobreza.

Como interpretar esses dados? Uma hipótese possível seria que as mudanças inspiradas no clima privatizador das últimas décadas não se expressam, todavia, nas cifras estatísticas globais, mas começaram a perceber-se com maior nitidez no futuro. Esta hipótese estaria apoiada no fato de que os países onde o ensino privado não existia (é o caso dos países do Leste europeu) começaram ou têm começado recentemente a permitir ou estimular seu desenvolvimento.

Mas a hipótese oposta também resulta plausível: na medida em que 
a incorporaçáo à economia de mercado efetua-se em condiçóes de notória escassez de recursos, a capacidade das famílias para assumir privadamente a escolaridade de seus filhos será, ao menos a curto prazo, relativamente baixa. Esta explicação também se aplica aos países afetados por crises econômicas prolongadas, ligadas ao alto endividamento externo.

Para o caso da América Latina, por exemplo, tem-se sugerido a hipótese segundo a qual a diminuiçáo do gasto público em educaçáo e a deteriorização das condiçóes materiais de vida dos setores de baixa renda estariam estimulando o incremento da demanda por educaçáo pública por parte dos setores que, no passado, lograram ter acesso a serviços educativos privados. A expansão do setor público em um contexto de diminuição de recursos orçamentários provoca o aumento da diferenciaçáo interna da oferta educativa. Segundo esta hipótese, o ensino público estaria assumindo características cada vez mais massivas, enquanto que a oferta privada assumiria características mais elitistas (4).

Se bem que a análise destas hipóteses exige maiores informaçóes, resulta plausível aceitar que a estabilidade da cobertura do ensino privado e certa tendência, em alguns casos, à diminuiçăo, podem ser consideradas fenômenos de curto prazo. A médio prazo, por outro lado, é provável que se assista a um ritmo mais acelerado de expansão da cobertura privada, através de fórmulas mistas e diversificadas. $A$ análise desagregada das cifras globais permitirá identificar algumas destas tendências e um contexto de enorme diversidade de situaçóes.

\section{As diversidades nacionais}

Os dados agregados apresentados no ponto anterior ocultam, obviamente, importantes diferenças entre países. A diversidade de situaçōes nacionais é significativamente alta e permite observar que não existe uma associaçăo unívoca entre ensino privado, modernizaçấo educativa e desenvolvimento econômico-social.

Nos quadros 4 e 5, apresentam-se informaçóes relativas à participaçáo privada na matrícula de ensino primário e superior em países da América Latina, segundo níveis de ingresso, e em alguns países selecionados, de alto nível de desenvolvimento.

A conclusão mais geral que se pode deduzir destes dados $e$, do ponto de vista da distribuiçăo da matrícula, nảo existir uma associaçáo unívoca entre ensino privado, modernização e desenvolvimento. Em termos muito gerais, poder-se-ia sustentar que existem dois padróes extremos de desenvolvimento: 


\section{Quadro 4}

Alunos de escola primária em escolas privadas. América Latina e outros países selecionados - 1965-1985.

\begin{tabular}{|c|c|c|c|c|c|}
\hline & 1965 & 1970 & 1975 & 1980 & 1985 \\
\hline \multicolumn{6}{|l|}{$\begin{array}{l}\text { Países de ingressos } \\
\text { medianos-baixos }\end{array}$} \\
\hline Bolívia & 25.9 & 15.8 & 8.8 & - & 7.7 \\
\hline República Dominicana & 7.3 & 11.6 & 12.2 & 17.8 & 24.1 \\
\hline Honduras & 6.6 & 5.9 & 5.2 & 5.3 & 5.1 \\
\hline Nicarágua & 15.7 & 15.1 & 13.3 & 11.8 & 13.3 \\
\hline El Salvador & 4.1 & 4.8 & 6.6 & 7.2 & 8.1 \\
\hline Guatemala & 19.1 & 15.5 & 13.6 & 14.2 & 13.7 \\
\hline Paraguai & 10.4 & 12.9 & - & - & 17.7 \\
\hline Equador & 18.4 & 17.9 & 16.9 & 15.9 & - \\
\hline Peru & 14.1 & 14.5 & 12.9 & 13.1 & 14.4 \\
\hline Colômbia & 14.0 & 13.4 & 15.2 & 14.5 & 13.5 \\
\hline Chile & 27.4 & 22.8 & 18.3 & 20.2 & 31.8 \\
\hline Costa Rica & 3.8 & 3.5 & 3.7 & 2.6 & 3.5 \\
\hline \multicolumn{6}{|l|}{$\begin{array}{l}\text { Países de ingressos } \\
\text { medianos-altos }\end{array}$} \\
\hline Brasil & 11.0 & 7.5 & 12.9 & 12.8 & 12.1 \\
\hline México & 9.5 & 7.8 & 6.0 & 4.9 & 5.0 \\
\hline Uruguai & 18.1 & 18.5 & 17.2 & 16.4 & 15.4 \\
\hline Panamá & 5.1 & 5.4 & 5.0 & 6.3 & 7.5 \\
\hline Argentina & 13.8 & 15.9 & 17.3 & 17.8 & 18.6 \\
\hline Venezuela & 13.0 & 11.7 & 11.1 & 11.1 & 11.5 \\
\hline \multicolumn{6}{|l|}{$\begin{array}{l}\text { Outros países } \\
\text { selecionados }\end{array}$} \\
\hline Japão & 0.5 & 0.6 & 0.6 & 0.5 & 0.5 \\
\hline Alemanha & 0.6 & 0.5 & - & - & 1.6 \\
\hline Reino Unido & 4.3 & - & - & 4.0 & 4.5 \\
\hline Bélgica & 53.7 & 54.0 & 51.6 & 53.0 & 54.6 \\
\hline Países Baixos & 73.8 & 72.5 & 70.2 & 68.3 & 68.5 \\
\hline Itália & 8.4 & 7.0 & 6.8 & 7.2 & 7.7 \\
\hline Espanha & 24.3 & 27.9 & 37.1 & 35.5 & 34.2 \\
\hline
\end{tabular}

FONTE: M. E. Lockheed e A. M. Verspoor - El mejoramiento de la educación primaria en los países en desarrollo: examen de las opciones de política. Banco Mundial, 1990. 


\section{Quadro 5}

Matrícula de ensino superior privado (\%) na América Latina e outros países selecionados, 1960-1985 (UAD).

\begin{tabular}{l|r|r|r|r}
\hline & 1960 & 1970 & 1980 & UAD \\
\hline $\begin{array}{l}\text { Países de ingressos } \\
\text { médios-baixos }\end{array}$ & & & & \\
Colômbia & 41.0 & 46.0 & 62.9 & $(84) 60.9$ \\
Costa Rica & 0 & 0 & - & $(85) 14.3$ \\
Chile & 37.0 & 34.0 & - & $(84) 32.3$ \\
Equador & 8.0 & 21.0 & 15.6 & - \\
Peru & 11.0 & 22.0 & - & $(84) 32.7$ \\
\hline Países de ingressos & & & & \\
médios-altos & & & & \\
Argentina & 2.0 & 17.0 & 21.7 & $(85) 16.1$ \\
Brasil & 44.0 & 55.0 & 64.3 & $(83) 58.7$ \\
México & 14.0 & 15.0 & - & $(82) 17.4$ \\
Venezuela & 11.0 & 11.0 & 11.6 & $(84) 16.8$ \\
\hline Outros países & & & & \\
selecionados & - & $(75) 79.0$ & 78.0 & $(89) 72.6$ \\
Japão & - & $(75) 63.0$ & 65.0 & $(86) 65.0$ \\
Bélgica & - & - & - & $(86) 10.0$ \\
Itália & & & - & $(86) 9.0$ \\
Espanha & & & & \\
Países Baixos & & & & \\
\hline
\end{tabular}

FONTES: Ver JCT - El desafio educativo, Quadro 8, pág. 120. Também Carmen Garća Guadilla "Expansión y diferenciación del sector privado de la educación superior en América Latina", em Educación Superior, no 26, julho-dezembro de 1988, Caracas, Cresalc.

OCDE - Education in OECD countries 1987-88: a compendium of statistical information. Paris, 1990.

1. O que se expressa através de uma concentração do esforço público no ensino primário, deixando um papel mais ativo para a atividade privada no ensino médio e superior.

2. O padrão inverso, onde o setor privado assume maiores quotas de responsabilidade no ensino primário e menos nos níveis pós-primários.

Estes padróes de comportamento refletem estruturas distintas de demanda educativa e, o que é mais importante, distintos modelos de distribuição social dos recursos públicos. O segundo destes padróes, 
vigente em vários países em desenvolvimento, constitui um padrão regressivo de distribuição de recursos, na medida em que canaliza uma proporção importante dos recursos públicos na educaçáo das elites provenientes das camadas médias e altas. A análise destes problemas também exige, no entanto, certo grau de desagregaçáo, tanto do ponto de vista do papel do setor privado nos diferentes níveis do sistema como da articulaçáo entre Estado e setor privado.

\section{Ensino privado, Estado e eqüidade social}

Começaremos pela análise do papel do Estado nos diferentes níveis do sistema. A esse respeito, parece-nos muito ilustrativo analisar dois casos nacionais diferentes: Japão e Brasil.

Os dados estatísticos resenhados nos pontos anteriores mostram que a política educativa japonesa tem-se caracterizado pelo forte rol do Estado em prover educaçáo básica para toda a populaçáo. Mas, também, é importante advertir sobre o rol igualmente forte do Estado na formação das elites. Se bem que, do ponto de vista quantitativo, o setor privado tem uma importância significativa nos níveis pós-secundários, desde o ponto de vista da qualidade sáo as instituiçóes públicas as que possuem maiores níveis de excelência e de prestígio. Esta característica do setor público deriva dos critérios de seleçáo no acesso, da diferenciação institucional que define o setor pós-secundário público japonês e de seu forte sentido hierárquico (5).

A reforma educativa iniciada pelo governo da cidade de Tóquio, em 1967 , destinada a resolver os problemas de iniqüidade que provocava o sistema de educação pública, eliminando esses critérios, produziu resultados ainda mais insatisfatórios. As conseqüências dessa experiência desestimularam a outros governos locais a segui-la e, ainda no mesmo distrito de Tóquio, foram deixadas de lado.

Benjamin e James, em sua obra citada, analisam essa experiência e apresentam o paradoxo dos sistemas distintos de garantir a eqüidade. Por um lado, um sistema público-elitista, que atrai estudantes das famílias de mais altos recursos mas que também permite a incorporaçáo de filhos de famílias de baixos recursos com alto desempenho acadêmico. No rol igualitário deste esquema fortalece-se, como é o caso japonês, a igualdade de oportunidades garantida por um sistema público homogêneo de educação básica. Por outro, um sistema público-igualitário que oferece similares possibilidades de acesso a todos, mas que outorga à educaçáo privada a possibilidade de atrair os filhos talentosos das famílias de altos recursos e converter-se, assim, no segmento de alta qua- 
lidade e prestígio do sistema educativo, do qual ficam excluídos os filhos de famílias de baixos recursos.

O outro exemplo interessante, de países em desenvolvimento, é o do Brasil. Os dados de distribuição da matrícula indicam que, apesar de os esforços públicos serem maiores na educaçáo básica que na superior, existe uma porcentagem importante de matrícula primária privada. No entanto, da mesma forma que no Japão, as universidades públicas são as que gozam de maior prestígio e nível de excelência. Esta articulaçáo tem permitido que o caso do Brasil apresente-se como típico de aplicaçáo regressiva dos recursos públicos em educação: os filhos das famílias de classe alta váo a escolas primárias e secundárias privadas de boa qualidade, onde obtêm a preparação que lhes permite passar nos exames exigentes das universidades públicas gratuitas. Os filhos das famílias de escassos recursos, por outro lado, recebern uma educação primária e secundária pública de baixa qualidade, que não os habilita para obter boas pontuaçóes nas provas de acesso à universidade e, portanto, devem pagar uma educação superior de baixa qualidade.

A grande diferença entre o Japão e o Brasil, ademais, obviamente, de seus níveis de desenvolvimento econômico, radica nos níveis de equiidade existentes na base do sistema educativo. Enquanto no Japão o Estado garante a todos uma escola primária homogênea, no Brasil ela

Em dia de tempo

bom, os alunos

da escola

primaria de

Ogawa

aproweitam para

almogar em estilo

"piquenique"

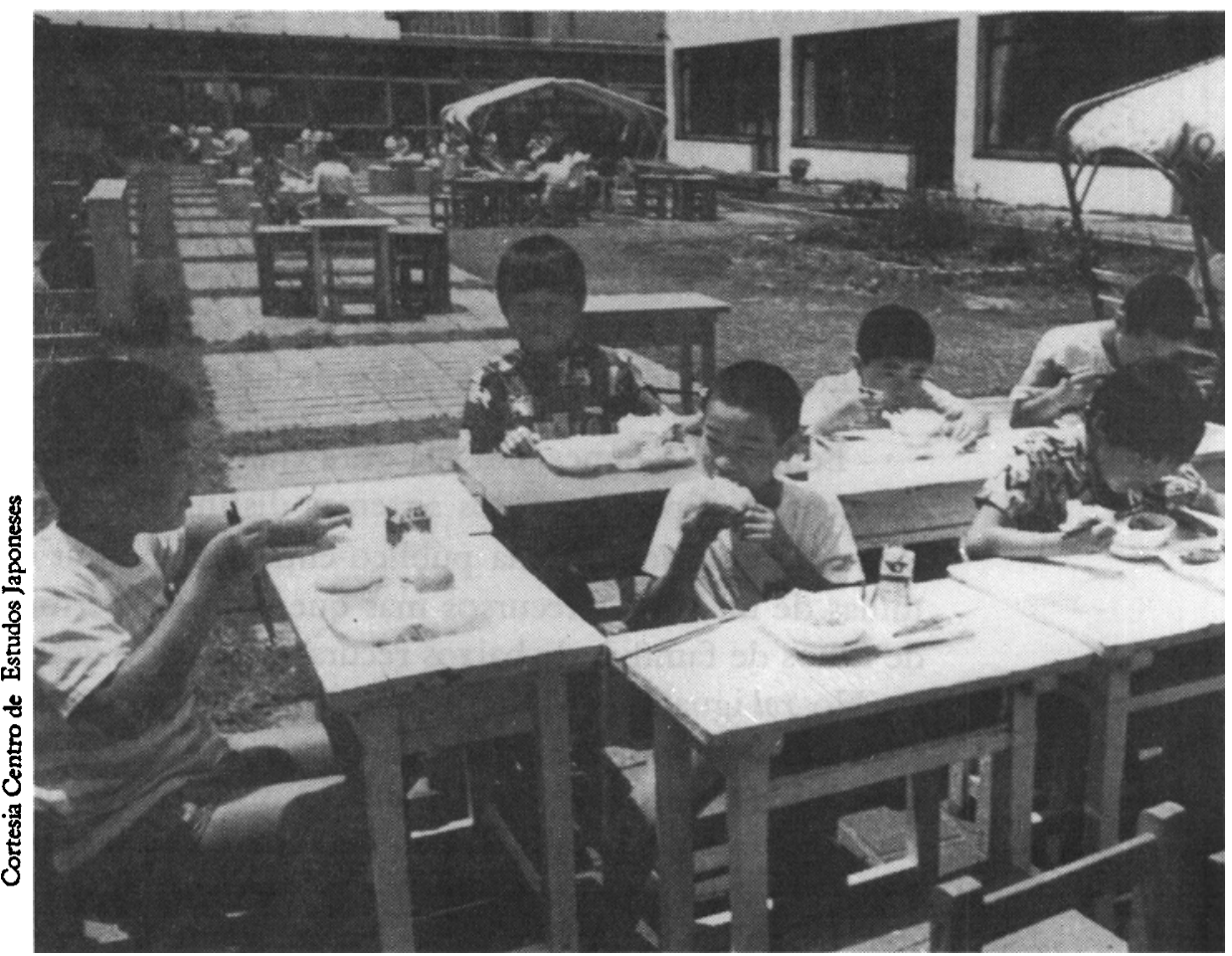

ESTUDOS AVANÇADOS 12(5), 1991 


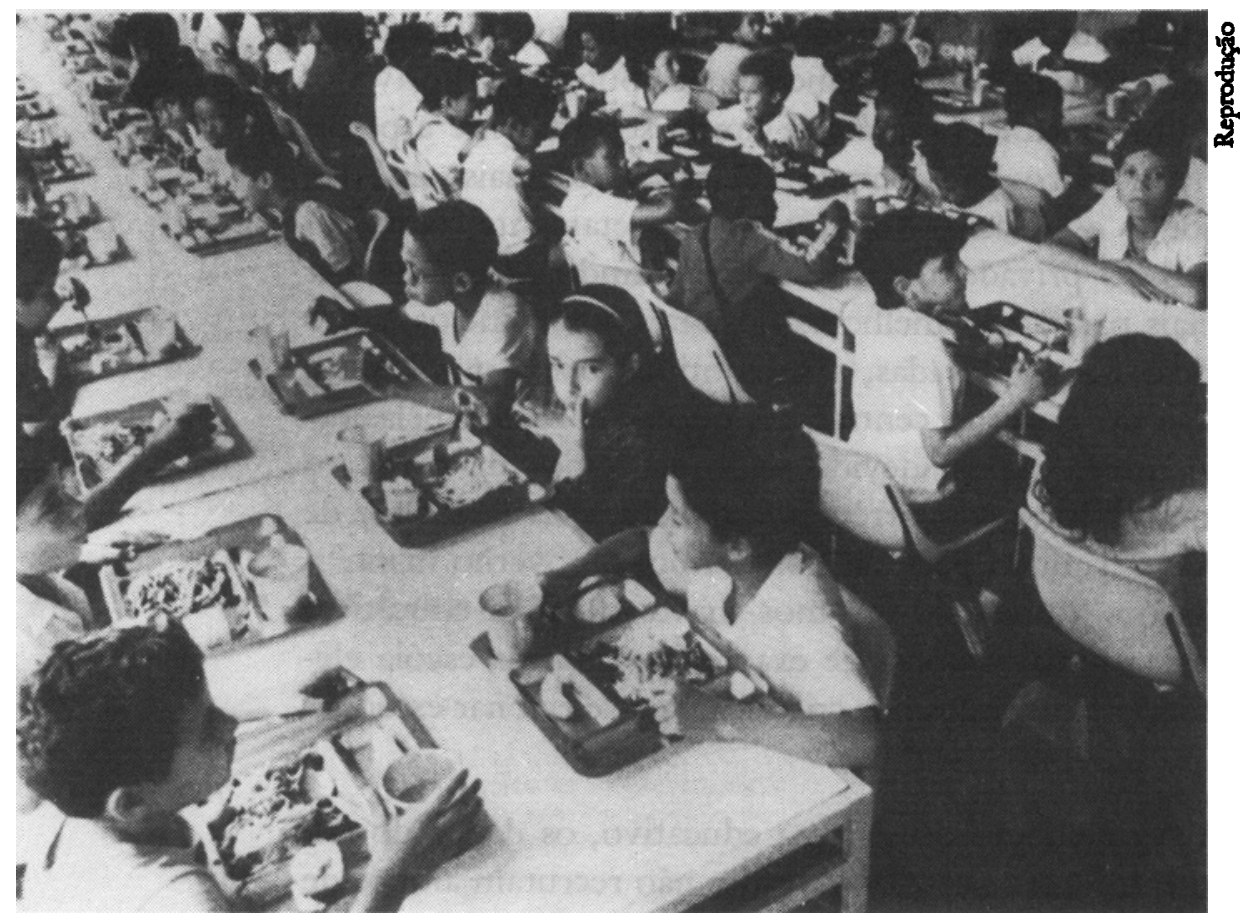

As crianfas

comem em

bandeijoes no

refeitorio de um

Centro

Integrado de

Educactio

Pública, no Rio

de Janeiro

está fortemente segmentada e o Estado não logra dar as bases da igualdade de oportunidades. Nestes casos, os mesmos resultados, no plano do ensino superior, têm significados muito diferentes se se analisa o conjunto do sistema educativo.

Mas as diferenças nacionais também refletem diferenças nas formas de articulaçăo entre setor público e privado. Deste ponto de vista, é interessante analisar o caso de países desenvolvidos com alta participaçáo privada na escola primária, mas com fortes controles estatais que regulam suas atividades. Neste sentido, a análise da experiência holandesa de privatizaçáo de serviços públicos reveste-se de grande interesse pelas fórmulas de combinaçăo que desenvolvem entre setor público e privado.

Historicamente, a origem da demanda por ensino privado esteve fortemente vinculada à heterogeneidade religiosa. Tanto a comunidade católica como a protestante demandaram ao Estado o apoio para poder oferecer a seus filhos uma educação no marco de seus códigos culturais. Separados porem iguais constituiu um componente central do sistema educativo holandês. Não somente educaçáo, como também saúde, partidos políticos, organizações sindicais, etc. foram organizados de forma separada segundo a pertinência a cada grupo religioso. Os grupos religiosos oferecem a maior quota de dinamismo e de capacidade empresarial no âmbito da educação privada. 
Do ponto de vista do financiamento, o sistema holandês caracteriza-se pela articulaçáo estrita entre o financiamento público e o privado. O Estado oferece um subsídio (voucher) e limita severamente a possibilidade de estabelecer outros pagamentos adicionais. Ademais, o governo central paga todos os salários dos docentes diretamente, tanto do setor público como do privado e não está permitindo às escolas dar suplementos salariais para atrair melhores docentes. Os edifícios, tanto para escolas públicas como privadas, são mantidos pelos municípios, mas com reembolso do governo central. As quotas cobradas pelas escolas privadas sáo muito baixas, devido tanto ao temor de perder 0 subsídio estatal como à forte concorrência, em virtude da facilidade de entrada no mercado permitida pela lei. Por último, o governo mantém fortes regulamentaçóes através de insumos-chaves de ação educativa: currículo uniforme, sistema nacional de exames no final da escola elementar e da secundária e controles nos critérios para selecionar estudantes.

Em relaçáo à segmentaçáo do sistema educativo, os dados do sistema holandês mostram que as escolas privadas não recrutam alunos de origens sociais distintas às das escolas públicas. As razóes desta baixa atração das escolas privadas são, precisamente, as restriçóes impostas pelo governo para outorgar subsídios: não existem, por exemplo, diferenças de salários dos docentes nem possibilidade de excluir estudantes que não possam pagar (6).

No caso dos países da América Latina, por outro lado, não se dáo situaçóes onde o setor privado jogue um papel quantitativamente táo significativo e onde o Estado aplique esses níveis de controle. No ponto seguinte, trataremos de ver detalhadamente o papel da educação privada em relação à eqüidade social, tomando o exemplo de alguns países da América Latina.

\section{Educação privada e democratização}

Tradicionalmente, os atores mais dinâmicos do setor educativo privado na América Latina são os diferentes grupos religiosos. Nos últimos anos, no entanto, o processo de secularização da sociedade e a crescente importância do conhecimento e da informação nos processos produtivos têm estimulado a participaçáo de novos atores com significativos níveis de dinamismo, que têm produzido maior diferenciação interna do setor educativo privado. Ademais da diferenciaçáo segundo o tipo de ator social (Igreja, empresa privada, grupos de pais, empresários educativos, etc.), também existe maior diferenciação nas formas 
de articulação com o Estado. A esse respeito, pode-se distinguir, ao menos, dois setores: o setor privado náo-subvencionado pelo Estado e o setor privado subsidiado.

Esta maior diferenciaçáo implica maiores níveis de democratização do ensino privado? Para responder a esta pergunta seria necessário dispor de informaçóes acerca da composição interna da matrícula de ensino privado por origem social dos alunos e modalidade de ação privada. Esta informação não existe na maioria dos países, mas pode-se obter uma visão aproximada deste problema através dos dados sobre matrícula pública e privada nas áreas urbanas e rurais. Esta informaçăo está disponível para o ano de 1989, na maior parte dos países da América Latina e Caribe, tendo sido resumida no Quadro 6.

\section{Quadro 6}

América Latina: Educação privada segundo zona. Nível pré-escolar e primário. Ano 1989 (porcentagens sobre a matrícula total em cada zona).

\begin{tabular}{l|r|r|r|r}
\hline & \multicolumn{3}{|c}{ pré-primária } & \multicolumn{2}{c}{ primária } \\
& \multicolumn{3}{|c|}{ urbana rural } & \multicolumn{2}{c}{ urbana rural } \\
\hline Bolívia & 15 & - & 30.3 & - \\
Brasil & 38 & 14 & 20.8 & 1.0 \\
Colômbia & 55 & 23 & 29.1 & 1.1 \\
Chile (a) & 38 & 14 & - & - \\
Equador & 43 & 14 & 34.2 & 6.4 \\
Paraguai & 61 & 19 & 39.1 & 10.1 \\
Peru & 24 & 11 & 13.0 & 5.5 \\
Uruguai & 44 & - & 22.9 & - \\
Venezuela & 20 & 1 & 32.0 & 0.7 \\
\hline Costa Rica & - & - & 22.4 & 0.4 \\
El Salvador & 34 & 20 & 32.0 & 1.9 \\
Guatemala & 46 & 26 & 43.7 & 10.8 \\
Honduras & - & - & 22.1 & 1.9 \\
Nicarágua & 16 & 6 & 25.4 & 2.7 \\
Panamá & 27 & 6 & 37.0 & 0.3 \\
\hline México & 10 & - & 11.7 & 0.2 \\
\hline
\end{tabular}

(a): ano 1987

FONTE: Orealc/Siri 
Os dados permitem observar que a forte concentraçáo da atividade privada nas zonas urbanas é um fenômeno que caracteriza todos os países da regiăo. Tal concentraçáo é significativamente mais alta no caso do ensino primário, o qual permite sustentar que nas zonas rurais o Estado é praticamente a única agência que oferece educaçăo.

A forte discriminação entre oferta educativa rural e urbana é um primeiro indicador do caráter segmentado da oferta educativa nos países latino-americanos. A interrogaçáo seguinte seria a que se refere à composição interna da oferta educativa urbana. Neste sentido, as investigaçóes parciais efetuadas em alguns países confirmam a hipótese do caráter segmentado do ensino privado (7). Ele recruta seu alunado em setores médios e altos, propiciando desta forma um fenômeno circular: alunos dotados de melhores backgrounds familiares recebem uma oferta escolar caracterizada por equipamentos e pessoal adequado, obtendo resultados mais altos que os produzidos pela escola pública. Em alguns casos, inclusive, os estabelecimentos privados não admitem alunos repetentes, cuja única alternativa é a escola pública, onde a alternativa de excluir um aluno por seu baixo rendimento, por princípio, náo pode existir.

Apesar desta forte concentração da oferta privada nos setores sociais médios e altos, existem casos onde a oferta privada é ampliada sobre a base de subsídios estatais. Como se sabe, 0 argumento para estimular este tipo de alternativa tem sido, habitualmente, um argumento financeiro. Segundo alguns estudos, resultaria mais barato para o Estado financiar um estabelecimento privado que ofereça educaçáo gratuita, que financiar uma escola pública. Trata-se, agora, de saber se, além da suposta vantagem financeira, também existem vantagens do ponto de vista dos resultados da ação pedagógica.

A informaçáo sobre este problema é muito parcial. Para o caso da América Latina, dispomos de dados que podem ser aproveitados para responder a esta pergunta em dois países: Chile e Uruguai. No caso do Chile, os dados correspondem aos resultados da aplicaçáo da prova do SIMCE em 1982 e 1988. No caso do Uruguai, os dados provêm do questionário aplicado no estudo da CEPAL antes citado.

No Quadro 7, resume-se a informação relativa ao rendimento dos alunos nas provas de Espanhol e Matemáticas de escolas privadas subsidiadas e de escolas municipais do Chile, segundo a origem social dos alunos e tamanho das cidades.

Estes dados devem ser analisados tendo em conta que o Chile vive um intenso processo privatizador nos últimos anos, convertendo esta 


\section{Quadro 7}

Chile: Rendimento em Espanhol e Matemáticas no $4^{\circ}$ Grau de escolas básicas, 1982-1988.

\begin{tabular}{|c|c|c|c|c|}
\hline $\begin{array}{l}\text { Tipo } \\
\text { de escola }\end{array}$ & $\begin{array}{l}\text { Nível } \\
\text { socioeconômico }\end{array}$ & $\begin{array}{l}\text { Tamanho } \\
\text { da cidade }\end{array}$ & $\begin{array}{l}\text { Espanhol } \\
1982-88\end{array}$ & $\begin{array}{c}\text { Matemáticas } \\
\text { 1982-88 }\end{array}$ \\
\hline \multirow[t]{2}{*}{$\begin{array}{l}\text { Privada } \\
\text { paga }\end{array}$} & Alto & $\begin{array}{l}\text { Metrop. } \\
\text { Grande }\end{array}$ & $\begin{array}{ll}72.0 & 69.3 \\
71.1 & 70.2 \\
\end{array}$ & $\begin{array}{ll}66.0 & 62.3 \\
60.7 & 62.1 \\
\end{array}$ \\
\hline & Médio & $\begin{array}{l}\text { Metrop. } \\
\text { Grande }\end{array}$ & $\begin{array}{ll}65.5 & 62.8 \\
62.8 & 60.6\end{array}$ & $\begin{array}{ll}56.8 & 50.8 \\
55.1 & 53.6\end{array}$ \\
\hline \multirow[t]{4}{*}{$\begin{array}{l}\text { Privada } \\
\text { subsidiada }\end{array}$} & Alto & $\begin{array}{l}\text { Metrop. } \\
\text { Grande }\end{array}$ & $\begin{array}{ll}53.8 & 55.7 \\
62.1 & 64.5\end{array}$ & $\begin{array}{ll}46.5 & 47.9 \\
54.2 & 55.9\end{array}$ \\
\hline & Médio & $\begin{array}{l}\text { Metrop. } \\
\text { Grande }\end{array}$ & $\begin{array}{ll}43.0 & 45.4 \\
46.6 & 50.0 \\
\end{array}$ & $\begin{array}{ll}35.5 & 37.4 \\
37.9 & 41.9\end{array}$ \\
\hline & Baixo & $\begin{array}{l}\text { Metrop. } \\
\text { Grande } \\
\text { Rural }\end{array}$ & $\begin{array}{ll}34.9 & 33.3 \\
31.0 & 31.1 \\
27.3 & 25.8\end{array}$ & $\begin{array}{ll}27.7 & 27.7 \\
23.7 & 27.6 \\
17.2 & 22.1\end{array}$ \\
\hline & Muito baixo & $\begin{array}{l}\text { Metrop. } \\
\text { Grande } \\
\text { Rural }\end{array}$ & $\begin{array}{rr}0.0 & 18.6 \\
0.0 & 17.7 \\
0.0 & 6.4\end{array}$ & $\begin{array}{ll}0.0 & 24.4 \\
0.0 & 20.2 \\
0.0 & 10.0\end{array}$ \\
\hline \multirow[t]{4}{*}{ Municipal } & Alto & $\begin{array}{l}\text { Metrop. } \\
\text { Grande } \\
\text { Rural }\end{array}$ & $\begin{array}{ll}59.1 & 0.0 \\
51.4 & 0.0 \\
48.6 & 0.0\end{array}$ & $\begin{array}{ll}47.1 & 0.0 \\
43.6 & 0.0 \\
42.7 & 0.0\end{array}$ \\
\hline & Médio & $\begin{array}{l}\text { Metrop. } \\
\text { Grande } \\
\text { Rural }\end{array}$ & $\begin{array}{ll}37.8 & 41.2 \\
42.7 & 44.9 \\
37.3 & 37.2\end{array}$ & $\begin{array}{ll}30.3 & 35.0 \\
35.7 & 38.9 \\
30.6 & 29.7\end{array}$ \\
\hline & Baixo & $\begin{array}{l}\text { Metrop. } \\
\text { Grande } \\
\text { Rural }\end{array}$ & $\begin{array}{ll}31.0 & 26.2 \\
34.3 & 27.5 \\
26.7 & 19.1\end{array}$ & $\begin{array}{ll}24.3 & 22.5 \\
26.8 & 24.8 \\
18.4 & 18.3\end{array}$ \\
\hline & Muito baixo & $\begin{array}{l}\text { Metrop. } \\
\text { Grande } \\
\text { Rural }\end{array}$ & $\begin{array}{ll}0.0 & 23.9 \\
0.0 & 16.2 \\
0.0 & 13.8\end{array}$ & $\begin{array}{ll}0.0 & 20.8 \\
0.0 & 17.2 \\
0.0 & 15.0\end{array}$ \\
\hline Total & & & $37.9 \quad 32.5$ & $30.5 \quad 28.6$ \\
\hline
\end{tabular}

FONTE: CPEIP, Série Estudos, n 81 e dados SIMCE, 1988. 
experiência em um caso demonstrativo das possibilidades desta estratégia como modelo a ser seguido em outros países. Duas conclusóes gerais podem ser feitas de uma primeira leitura dos dados. A primeira, obviamente, é a forte segmentaçáo que existe no interior do sistema, onde o segmento superior logra níveis de rendimento três vezes superior ao inferior. A segunda, menos óbvia que a anterior, é que a qualidade média, através dos indicadores de rendimento nas provas aplicadas nos anos mencionados, não tem melhorado em nenhum dos segmentos.

Mas, se concentrarmos a atençáo no comportamento dos alunos de setores baixos segundo a educaçáo que recebem em escolas municipais ou privadas subsidiadas, é possível observar alguns fatos interessantes. Em relação ao ensino de Espanhol, as escolas privadas obtêm resultados melhores que as municipais, nos alunos de estratos baixos, mas no caso dos de estratos muito baixos, a tendência se inverte. No caso das Matemáticas, por outro lado, o comportamento é mais regular. Em termos gerais, no entanto, os dados parecem confirmar a hipótese segundo a qual as escolas privadas gratuitas logram compensar as diferenças melhor que as públicas, sem que isso signifique, em nenhum caso, que esta opção logre superar a barreira de origem social na determinação do rendimento educativo.

Mas, para o caso do Chile, esta análise deve ser ampliada com a informaçáo referente ao rendimento das escolas privadas segundo sua antigüidade. Como se sabe, o processo de privatizaçáo educativa no Chile foi muito intenso nos últimos anos, durante o qual se estimulou a criação de estabelecimentos através de incentivos financeiros. As novas escolas privadas se distinguem das tradicionais: pela importância do lucro econômico e pela motivaçáo da sua criação.

Os dados do SIMCE para a cidade de Santiago, na última prova aplicada, permitem observar um fenômeno interessante: as escolas privadas criadas nos últimos dez anos obtêm resultados significativamente inferiores às que têm mais de 10 anos de idade, provavelmente porque carecem de tradição pedagógica mas, ademais, porque recrutam seu alunado em famílias de origem social mais baixa (Quadro 8).

Em definitivo, estes dados mostram que as novas escolas privadas subsidiadas se parecem mais com as escolas públicas que as antigas escolas privadas, tradicionalmente receptoras dos filhos das famílias de classe média e alta. Sobre esta base, seria possível sustentar a hipótese segundo a qual, nos casos onde existe oferta educativa privada dirigida a setores sociais de baixos recursos, tal oferta é pobre do ponto de vista de suas possibilidades compensadoras. 


\section{Quadro 8}

Santiago do Chile: Rendimento em estabelecimentos particulares subvencionados segundo idade e em estabelecimentos municipais.

\begin{tabular}{l|c|c|c|c}
\hline & EMS & EPS (-10) & EPS (+10) & EPP \\
\hline Espanhol & 56.6 & 62.5 & 63.7 & 79.2 \\
Matemáticas & 55.2 & 58.6 & 62.3 & 78.7 \\
\hline
\end{tabular}

EMS: Escolas municipais, EPS: Escolas privadas subvencionadas e EPP: Escolas privadas pagas.

A pesquisa levada a cabo no Uruguai permite analisar fenômenos diferentes aos analisados para o caso do Chile, mas igualmente significativos.

O Uruguai é um país de expansão escolar prematura, em um contexto de forte hegemonia do setor público, tradicionalmente considerado como de alta qualidade. A crise econômica e institucional que vive o país há mais de uma década transformou profundamente as bases tradicionais do sistema social. No que aqui nos interessa, é importante destacar que o papel da educaçáo privada no nível primário tem sido sempre relativamente baixo (17.2\% em 1975 e $15.6 \%$ em 1989), mas a crise provocou um descenso ainda maior de sua cobertura, que afetou principalmente os setores médios da sociedade. A esse respeito, uma comparaçáo da assistência a escolas públicas ou privadas da cidade de Montevidéu, segundo níveis de ingresso, entre os anos de 1981 e 1988, mostra que a proporçáo de alunos que assiste a escolas privadas pagas descendeu em todas as faixas de ingresso, com exceçáo da faixa superior (7).

Os resultados das provas de rendimento em Matemáticas e em Espanhol, aplicadas à amostra de escolas de diferentes estratos, têm sido exaustivamente analisados pelo informe da CEPAL. O mais impactante - considerando a tradição educativa do Uruguai - é o muito baixo nível de compensação de diferenças logrado pela escola frente às diferenças socioeconômicas das famílias. No entanto, a análise desagregada dos dados permite identificar que o setor de escolas que produz maior número de mutantes, isto $e$, alunos de origem socioeconômica baixa que logram resultados de aprendizagem satisfatórios, provém de um grupo de escolas públicas de uma cidade do Interior do país. Em tais escolas existe uma série de características institucionais (personalidade do diretor, tradições pedagógicas dos docentes e impossibilidade de impunidade social frente aos resultados pelo contato direto entre docentes e pais de família), que explica estes resultados positivos. 
Em síntese, os resultados aportados por estes dois casos nacionais indicam que a explicaçáo de bons resultados de aprendizagem em alunos provenientes de famílias de baixos recursos não radica tanto no caráter estatal ou privado, mas sim na dinâmica institucional do estabelecimento escolar. Os melhores rendimentos parecem estar associados à possibilidade de definirem o projeto educativo do estabelecimento escolar, determinado pela consciência de objetivos fixados, pela existência de certas tradiçốes e metodologias de trabalho compartilhadas, espírito de equipe e responsabilidade pelos resultados, quer dizer, pela identidade institucional. As reflexóes finais deste trabalho apontam, por isso, nessa direçăo.

\section{A autonomia dos estabelecimentos}

A proposta central deste artigo consiste em sustentar que o eixo de discussão da dinamizaçáo do sistema educativo não radica tanto na questão do caráter privado ou estatal dos estabelecimentos, mas sim nos estilos de gestáo que caracterizam um ou outro segmento da oferta educativa. A realidade dos países em desenvolvimento demonstra que o

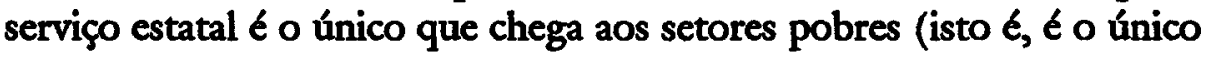
setor público do ponto de vista da populaçáo a que atende). Mas essa mesma experiência mostra que a forma com a qual o Estado enfrenta o desafio de oferecer este serviço é ineficiente e excludente. Inversamente, o setor privado possui uma dinâmica de gestáo que lhe permite ser eficiente, criativo e flexível, mas está dirigido somente aos setores sociais mais favorecidos.

Frente a esta situação, existiriam duas formas diferentes de enfrentar o problema:

1. definir uma estratégia destinada a introduzir democracia no setor privado; ou

2. definir uma estratégia destinada a introduzir o dinamismo da oferta privada no setor público.

As estratégias mais comuns destinadas a democratizar o funcionameento do setor privado consistem em: subsidiar escolas administradas por particulares ou apoiar, com programas de bolsas, 0 acesso de alunos de famílias pobres aos estabelecimentos privados.

Para introduzir dinamismo na gestáo pública, por outro lado, atualmente tem-se generalizado o consenso acerca das potencialidades das estratégias de descentralizaçáo e de maior autonomia aos estabelecimentos. 
Em apoio a esta linha de ação, argumenta-se que as estratégias tradicionais baseadas em melhorar homogeneamente os insumos (salários de professores, equipamentos, textos, currículo, etc.) não têm dado resultados positivos devido, entre outros fatores, à heterogênea situação dos estabelecimentos. $O$ peso com o qual cada insumo deve ser melhorado e o momento preciso no qual esta melhora deve ser efetuada dependem das condições locais. As decisóes deste tipo, em conseqüuência, também devem ser tomadas a nível local.

Ademais, esta estratégia apóia-se no pressuposto segundo o qual o funcionamento da escola tem um impacto significativo na explicação dos resultados escolares. O debate acerca desta afirmaçáo ocupa um lugar importante na investigação e na ação político-educativa recente. $O$ balanço dos conhecimentos acumulados neste campo mostra que o papel do estabelecimento é significativo, embora não seja possível, ainda, determinar com precisão quais são os fatores decisivos nesta dinâmica institucional. No entanto, mais além das discussóes sobre o impacto da escola, existe consenso em reconhecer que tal impacto está associado a certas características que podem ser incluídas no conceito de identidade institucional.

Em alguns casos, este conceito de identidade institucional associase com o que alguns autores denominam clima institucional, e outros, mais dentro da tradição francesa, de projeto por estabelecimento (8). As possibilidades de estimular esta linha de ação estão estritamente associadas à maior autonomia institucional que se outorgue aos estabelecimentos.

O debate sobre estes temas ocupa uma crescente atenção, tanto nos países desenvolvidos com nos países em via de desenvolvimento. No caso dos países desenvolvidos, obviamente, a maior ênfase nesta linha de ação provém dos países de forte tradiçáo centralista, particularmente os países europeus. Nos países saxôes, com forte descentralização em sua administração estatal, por outro lado, os problemas referem-se mais a como garantir mínimos homogêneos de qualidade. Mas o debate dos países desenvolvidos parte de uma base comum: a fortaleza dos atores locais, tanto do ponto de vista econômico quanto cultural (9).

Nos países em desenvolvimento, por outro lado, as possibilidades de lograr maior dinamisno, a partir de outorga de níveis mais altos de autonomia aos atores locais, ou de democratizar o setor privado, através de subsídios, choca com a forte heterogeneidade interna da estrutura social. Neste sentido, o ponto sobre o qual é preciso chamar permanentemente a atençăo é o que se refere tanto à desigualdade de distribuiçáo dos recursos materiais, e da capacidade de expressar demandas para ga- 
rantir sua satisfação, como à própria debilidade do Estado para garantir uma articulaçáo com o setor privado que garanta altos níveis de controle social sobre o uso dos recursos públicos.

Em definitivo, nos países em desenvolvimento, não está plenamente confirmada a hipótese segundo a qual outorgar maior autonomia aos atores locais é um efetivo mecanismo de dinamização. Algumas experiências de municipalização da oferta educativa póem de manifesto que as características do poder local podem ser um fator tão forte de rigidez como a oferta centralizada. Deste ponto de vista, em conseqüência, o dilema que enfrentam as políticas de descentralização e de maior autonomia às instituições é o de sua operacionalizaçăo. Qual é o momento oportuno e/ou quais sáo os pré-requisitos que devem existir para que a decisão de outorgar autonomia não seja um salto no vazio?

A esse respeito, a hipótese que este trabalho intenta postular é que o ponto central em toda política de autonomia pedagógica é o que se refere a pessoal, já que autonomia institucional implica autonomia profissional por parte do pessoal docente.

A situação dos países em desenvolvimento, em relaçáo a estes pontos, é muito heterogênea. Há países com forte tradiçáo de escolas públicas de excelente qualidade, com docentes altamente profissionalizados. Mas, também, e mais freqüentemente, é a situação inversa, reforçada pelas tendências dos últimos anos de deteriorização das condiçóes de trabalho dos docentes, a desprofissionalização e o abandono da profissão docente por parte dos mais qualificados. A interrogação, do ponto de vista da definição de políticas, consiste em definir se é preciso primeiro profissionalizar para logo dar autonomia ou, ao inverso, a autonomia institucional deve ser o primeiro passo para lograr maiores níveis de profissionalização.

Em realidade, obviamente, estas opçóes excluem os extremos e o debate coloca-se ao redor das ênfases e na sequiência das açóes. Tal debate, ademais, não pode dar-se somente, nem principalmente, a partir de uma perspectiva acadêmica. As variáveis mais importantes são as que se referem às especificidades políticas nacionais. Neste sentido, é importante destacar que o problema central situa-se no Estado e em sua capacidade para exercer suas funçóes de regulamentação, de avaliação de resultados e de dotação prioritária de recursos para os setores mais estratégicos, do ponto de vista do desenvolvimento econômico e de eqüidade social (10).

No entanto, há, ao menos, dois pontos sobre os quais é preciso chamar atençáo e analisar os resultados de experiências concretas: 1) o 
igualitarismo com o qual se considera os docentes, sem relação com os resultados, o qual priva o sistema de um mecanismo fundamental de eficiência; 2) o novo rol dos diretores das escolas, que deve deixar de ser predominantemente um executor de instruçōes uniformes para passar a ser um gestor e um criador de alternativas apropriadas.

Ambos os temas, é fácil percebê-los, têm um forte componente político. No entanto, a necessidade política tem criado muitos novos objetos de conhecimento científico. Este pode, sem dúvida alguma, ser um destes novos objetos a construir e, portanto, a estudar.

\section{Notas}

1 UNESCO - Development of private enrolment. First and second level education, 1975-1985. Division of Estatistics on Education. Paris, may 1989.

2 World Bank. Financing Education in Developing Countries: An Exploration of Policy Options. Washington, D.C., 1986.

3 Maria da Conceição Tavares, "Reestructuración industrial y políticas de ajuste macroeconómico en los centros (la modernización conservadora)", em Roberto Russell (ed.) - El Sistema Internacional y América Latina: La Agenda Internacional en los Anos 90. Buenos Aires, GEL, 1990.

4 Juan Carlos Tedesco, El desafio educativo: calidad e democracia. Buenos Aires, Grupo Editor Latinoamericano, 1987.

5 Estas reflexōes estão baseadas em Gail R. Benjamin e Estelle James - "Public Policy and Private Education in Japan", Londres, Macmillan, 1988. Um resumo deste livro pode ser encontrado no artigo dos mesmos autores "Public and Private Schools and Educational Opportunity in Japan", em James J. Shields (ed) - "Japanese Schooling; Patterns of socialization, Equality and Political Control", The Pennsylvania State University, 1989.

6 Estelle James, "Benefits and Costs of Privatized Public Services: Lessons form the Dutch Educational System", em "Comparative Education Review", v. 28, n 4, 1984.

7 Ver CEPAI, "Enseñanza primaria y ciclo básico de educación media en el Uruguay". Montevideo, 1990. G. Bronfenmajer y R. Casanova, "La diferencia escolar" . Caracas, Kapelusz, 1988.

8 CEPAL, op. cit.

9 Uma interessante recompilação de estudos sobre o tema da autonomia das escolas para o caso europeu em geral e italiano em particular pode ser encontrada em F. E. Crema e G. Pollini (ed), "Scuola, autonomia, mutamento sociale". Roma, Armando, 1989. Para o caso dos Estados Unidos, ver John E. Chubb e Eric A. Hanushek, "Reforming Educational Reform", em Henriy J. Aron (ed), "Setting National Priorities; Policies for the Nineties". Washington, D.C., The Brookings Institution, 1991. 
10 Uma análise inicial sobre o rol do Estado na educaçäo pode ser encontrada em dois textos anteriores sobre este tema: Juan Carlos Tedesco, "El rol del Estado en la educación", em Perspectivas, v. XIX, n 4, 1989 e Juan Carlos Tedesco, "Educación y estrategias de desarrollo: el desafio de la gestión pública", em Pensamiento Iberoamericano, Revista de Economia Pollíca, Madrid, no 19, 1991.

\section{Resumo}

O artigo discute os argumentos que propóem a privatizaçảo como eventual estratégia para a área educacional; apresenta dados sobre a evoluçäo do setor privado em várias regióes do mundo e as diversidades nacionais na relação público X privado na educaçáo. Analisa o papel do setor privado na oferta de ensino a setores populares com base em informaçăo sobre resultados de aprendizagem. Levanta a hipótese de que a eficiéncia da escola dependeria menos do caráter público e mais do seu grau de autonomia e identidade institucional. Conclui abrindo a discussāo sobre autonomia escolar e apresentando dúvidas e interrogaçóes que essa estratégia provoca.

\section{Abstratc}

The article discusses the arguments that propose the privatization as a strategy for education; shows data on both the evolution of the private education worldwide and the national diversity int the "public x private education" relation. It analizes the role played by the private sector in giving grassroots acess to education. It raises the hypothesis that the efficiency of education might depend less on the public character and more on its degree of autonomy and institutional identity. It concludes by opening the discussion about the educational autonomy and raising the doubts caused by this estrategy.

Juan Carlos Tedesco é diretor da Oficina Regional de Educação para a América Latina e Caribe (OREALC-UNESCO), em Santiago do Chile.

O autor agradece os comentários de Guiomar Namo de Mello, e de seus colegas da OREALC-UNESCO. Ernesto Chifelbein, Juan Cassasus, Rodrigo Vera, José Rivero, David Silva, Miguel Nuñes, Graciela Messina, Edmundo Fuenzalida e Arturo Matute, assim como Sonia Peruzzi, nos aspectos estatísticos. As opiniốes aqui expressas são, no entanto, de inteira responsabilidade do autor e năo comprometem a UNESCO.

Tradução de Ana Paula Cantanhede de Araújo. O original em espanhol encontra-se à disposiçäo do leitor no IEA para eventual consulta. 